\title{
Survival after aortic valve replacement vs. conservative management in severe low-flow, low-gradient aortic stenosis
}

\author{
Linda Renata Micali ${ }^{1}$, Salma Algaroosh ${ }^{1}$, Orlando Parise ${ }^{1}$, Gianmarco Parise ${ }^{1}$, Francesco \\ Matteucci $^{1}$, Monique de Jong ${ }^{1}$, Amalia Ioanna Moula ${ }^{1}$, Cecilia Tetta ${ }^{1}$, and Sandro \\ Gelsomino $^{1}$ \\ ${ }^{1}$ Maastricht University
}

June 18, 2020

\begin{abstract}
Background and aim. Classical and paradoxical low-flow, low-gradient aortic stenosis (LFLGAS) are the most challenging aortic stenosis (AS) subtypes. The current therapeutic options are aortic valve replacement (AVR) and conservative management. The matter is controversial because AVR promotes long-term survival, but it is invasive, while no aortic valve replacement (noAVR) in non-invasive, but it is associated with poor prognosis. This meta-analysis aims to investigate the survival rate in patients with LFLGAS undergoing AVR versus noAVR interventions. Methods. A meta-analysis was conducted comparing the outcomes of AVR and noAVR in terms of survival. A meta-regression was carried out to investigate the impact of preserved and reduced left ventricular ejection fraction (LVEF) on survival in both the AVR and noAVR group. Results. The log IRR of survival between AVR group and noAVR group was 0.58 [0.28, 0.87] (p-value $=0.0001$ ), suggesting that survival is significantly better in the AVR group compared to the noAVR group. The meta-regression revealed that low LVEF is related to higher survival rates in the AVR group ( $\mathrm{p}$-value $=0.04$ ) when compared to preserved LVEF. LVEF has no impact on survival in the noAVR group ( $\mathrm{p}$-value $=0.18$ ). Conclusions. Patients with LFLGAS have better survival in the AVR group rather than in the noAVR group. Reduced LVEF was related to better survival than preserved LVEF in the AVR, and no difference between low and preserved LVEF was found in the noAVR group.
\end{abstract}

\section{Introduction}

Low-flow, low-gradient aortic stenosis (LFLGAS) is the most challenging aortic stenosis (AS) subtype, regardless of whether it is accompanied by either depressed left ventricular ejection fraction (LVEF) or preserved $\mathrm{LVEF}^{1,2}$. The challenge derives from the inconsistency between aortic valve area (AVA) and gradient, which does not allow a realistic evaluation of the entity of the stenosis, fundamental in choosing the right therapeutic approach ${ }^{3}$.

Currently, the available therapeutic managements for LFLFAS are aortic valve replacement (AVR) in symptomatic patients with left ventricular (LV) dysfunction, and conservative management ${ }^{4}$. AVR promotes long-term survival and improvement of the functional status of patients in both classical and paradoxical LFLGAS. Still, it is more invasive, and it is associated with high operative mortality risk in patients with reduced LV contractile reserve ${ }^{4-7}$. On the other hand, a noAVR approach mainly via medical management is considered the treatment of choice in elderly patients and subjects with high preoperative risk, as it is not invasive ${ }^{8}$. However, noAVR approaches predispose patients to a poorer prognosis in both classical and paradoxical LFLGAS ${ }^{8}$. 
Since noAVR approach leads to a poor prognosis and AVR is burdened by a high operative risk, literature reports controversial results about the superiority of one type of management over the other.

Therefore, this meta-analysis aims to investigate the survival rate in patients with LFLGAS undergoing AVR versus noAVR interventions.

\section{Materials and methods}

\section{Search strategy}

We conducted our study using the Preferred Reporting Items for Systematic Reviews and Meta-Analyses (PRISMA) investigation guidelines. We searched for all available articles that reported the survival rate in patients with LF LG AS following either AVR or no $\mathrm{AVR}^{9}$. A literature search was conducted in Embase and Medline databases through PubMed, as well as Google Scholar and Cochrane library. Moreover, we checked the relevant articles which are suggested on those databases as well as the references of the selected materials. We used both free text words and MeSH terms.

The search terms were "Therapy/Broad[filter]" AND "Aortic Valve Stenosis" OR "Aortic Valve Stenosis [MeSH Terms]" OR "Aortic Stenosis" OR "Aortic Stenosis [MeSH Terms]" AND "Low Flow" OR "LowFlow" AND "Low Gradient" OR "Low-Gradient" AND "Aortic Valve Replacement" OR "Aortic Valve Replacement [MeSH Terms]" AND "Conservative Management" OR Conservative Management [MeSH Terms]" OR "Medical Treatment" OR "Medical Treatment [MeSH Terms]" AND "Surgical Intervention" OR "Surgical Intervention [MeSH Terms]" AND "Low-Flow Low-Gradient" OR Low Flow Low Gradient."

\section{Selection criteria}

We included articles that met the following criteria: (a) performed on humans, (b) studies with more than 20 patients, (c) articles comparing AVR to noAVR procedures, (d) articles focused on LF LG AS, (e) studies published in English and (f) articles published within the last 15 years (2004 - 2019). On the other hand, we excluded articles with the following conditions: (a) performed on animals, (b) not in English, (c) case reports (d) literature reviews and meta-analyses, (e) population study of 20 or less, (f) articles that are older than 15 years, (g) studies not focusing on LFLGAS (h) studies which did not report a comparison between AVR and no AVR.

\section{Methodological quality assessment}

To assess the quality of the included studies, we used a modified tool of Down and Black's Checklist for Measuring Quality ${ }^{10}$. This tool consists of 18 questions evaluating five criteria: (a) the overall quality of the study, (b) the external validity, (c) study bias, (d) confounding and selection bias, and (e) power of the study. Each question is graded on a binary basis ( 0 or 1$)$ except for two items, ranked out of 2 and out of 5 , respectively.

Two researchers (SA And LM) conducted the evaluation. A third researcher was involved in reviewing (OP). The agreement was quantified using Cohen's kappa ${ }^{11}$. 


\section{Endpoints}

The primary endpoint of our study was the survival rate at follow up in patients with LFLG AS, treated with AVR or noAVR. Also, we aimed to investigate the impact of LVEF on survival. In the AVR group, we included both surgical valve replacement (SAVR) and transcatheter valve replacement (TAVR), while in the no AVR group, we included conservative medical management and valvuloplasty ${ }^{3}$.

LFLGAS was defined as an aortic valve area (AVA) of [?]1 $\mathrm{cm}^{2}$ or indexed AVA $<0.6 \mathrm{~cm}^{2} / \mathrm{m}^{2}$, a stroke volume indexed (SVI) [?] $35 \mathrm{~mL} / \mathrm{m}^{2}$ and a transvalvular mean pressure gradient [?] $40 \mathrm{mmHg}$. Preserved LVEF was identified as > 55\% (paradoxical LFLGAS), while reduced LVEF was defined as $<50 \%$ (classical LFLGAS) ${ }^{3}$.

\section{Statistical analysis}

This meta-analysis was conducted using V.3.6.1 (R Foundation for Statistical Computing, Vienna, Austria). We used Incidence Rate (IR) and proportions as main statistical indexes. Since the follow-up time was different in each article, we employed the IR test to analyze survival rates in both groups. Heterogeneity was evaluated by using the I-square test, and the publication bias was evaluated by using the Egger regression test. Furthermore, meta-regression was performed to evaluate the impact of LVEF on survival in both AVR and the noAVR group. We defined statistical significance for $\mathrm{P}$ values $<0.05$.

\section{Results}

\section{Characteristics of the studies}

The steps that we followed in selecting the articles are shown in the PRISMA flow diagram in Figure 1 . In total, we found 49 articles. After the selection process, we retrieved four papers, and nine articles were added manually from the references of the formers. In the end, the final number of the included in our meta-analysis was 13 articles ${ }^{14-26}$.

The overall population size was 2,013 patients, 1,066 (53\%), and 947 (47\%) in the AVR and noAVR group, respectively. The baseline characteristics of the included patients are shown in Table 1 . Twelve papers defined whether their cohort of patients presented preserved or reduced LVEF 14-21,23-26. Out of 1,533 patients, $952(62.1 \%)$ patients had preserved LVEF, and $581(37.9 \%)$ had low LVEF. The mean age of the total population was 74.9 [73.3-76.6] years old ${ }^{14-18,20-23,25,26}$, particularly 73.2 [69.7-76.7] years old in the AVR group and 77.7 [74.8-80.7] years old in the noAVR group. Overall AVA was $0.81[0.77-0.84] \mathrm{cm}^{2}$ 14-18,20-23,26; overall mean gradients was 27.21 [24.43-29.98] $\mathrm{mmHg}^{14-18,20-23,26}$; overall SVI was 34.82 [27.61$42.04] \mathrm{mL} / \mathrm{m}^{2}$ 15-18,20,21,23,26.

The determination of the number of patients undergoing either SAVR or TAVR was conducted on 11 papers 14-21,23,25,26. The number of patients treated with SAVR was 607 (81.7\%), while $136(18.3 \%)$ patients received TAVR (Table 2 ). In the noAVR group, the majority of patients were treated medically rather than with valvuloplasty $(99.9 \%$ vs. $0.1 \%)$.

\section{Methodological quality}

The average overall quality rating was $0.81 \pm 0.53$, with ratings ranging from 0 to 1.81 . Appendix A illustrates the average scores on the elements of the checklist. The analysis revealed lower scores related to the internal validity for both bias and selection bias, and for power analysis, which is related to the quality 
of reporting. The low values shown are due to the study type being a retrospective with no randomized samples validity studies. Acceptable interrater agreement was found $(\varkappa=0.89 ; \%$-agree $=94.9)$.

\section{Follow up}

The mean follow up period, calculated in 9 papers, was 35.66 [27.50- 43.81] months ${ }^{14-18,20,21,25,26}$. The longest follow up period was 55.2 months ${ }^{17}$. Follow up was $100 \%$ complete in 9 studies ${ }^{14-17,19,20,23-25}$.

\section{Main endpoints}

Figure 2A shows that the log IRR of survival between AVR group and noAVR group was 0.58 [0.28, 0.87] $(\mathrm{p}$-value $=0.0001 ;$ I-square $=24.16 \%, \mathrm{p}$-value $=0.25 ;$ Egger's test: $0.18[-0.18,0.55], \mathrm{p}$-value $=0.002)$. This suggests that the overall survival is significantly better in the AVR group compared to the noAVR group. The funnel plot is shown in Figure 2B (funnel plot asymmetry test: p-value $=0.10$ ). Moreover, the meta regression revealed that low LVEF is related to higher survival rates in the AVR group ( $\mathrm{p}$-value $=0.04$ ) when compared to preserved LVEF (Figure 3A ). Conversely, LVEF has no impact on survival in the noAVR group (p-value $=0.18$ ), as shown in Figure 3B .

\section{Discussion}

Low flow, low gradient aortic stenosis (LFLGAS) is associated with a higher risk of a cardiac event and heart failure, increasing the rate of all-cause mortality, cardiovascular- and valvular-related death ${ }^{27}$. Aortic valve replacement (AVR) is effective in either classical or paradoxical LFLGAS ${ }^{28}$. AVR has shown to be able to reduce the rate of adverse events and improve left ventricle ejection fraction (LVEF), enhancing long-term survival when compared to non-aortic valve replacement (noAVR) approaches. However, in patients with concomitant coronary artery disease (CAD and reduced contractile reserve $(\mathrm{CR})$, the preoperative risk is too high to opt for AVR 29,30. In these cases, medical management is the recommended alternative approach, despite its reduced long-term survival rates ${ }^{31}$. The aim of techniques alternative to AVR is to treat patients who are inoperable because of concomitant life-threatening comorbidities and the reduced life expectancy ${ }^{32}$. The therapy has more palliative purposes, and it is per se related to complications such as stroke, aortic regurgitation, myocardial infarction ${ }^{33}$, restenosis, and deterioration of the aortic valve (AV) ${ }^{34,35}$.

The main finding of your meta-analysis is the superiority of AVR over noAVR in enhancing survival in patients with LFLGAS. Our result is consistent with studies reporting improved outcomes following AVR rather than noAVR ${ }^{36}$. AVR bears an elevated preoperative risk, but its benefits still outweigh the disadvantages when compared to noAVR. This is attributable to the fact that in high-risk patients with low life expectancy, medication with or without valvuloplasty represents a mere palliative cure not aimed at achieving therapeutic responses. NoAVR approach is mainly oriented towards the management of the cardiovascular risk factors, which include controlling hypertension and volume status. Furthermore, the low survival rate in the noAVR group could be the result of the increased risk of restenosis after valvuloplasty, which leads to deterioration of the valve already after one year ${ }^{37,38}$. Indeed, if, on the one hand, valvuloplasty reduces the transvalvular pressure gradient and improves symptoms, on the other hand, the post-valvuloplasty AVA does not exceed $1.0 \mathrm{~cm}^{2} 33,39$. Moreover, our result could have been influenced by the employment of the TAVR technique in some of the patients included in our analysis, as TAVR has better survival rates than SAVR as well as better LVEF recovery ${ }^{3,40,41}$.

The second finding of our meta-analysis was the increased survival at follow up in patients with reduced LVEF compared to those with preserved LVEF in the AVR group. Despite this could be initially counterintuitive, it is critical to acknowledge that it has been widely proved that LV dysfunction is present even with 
preserved LVEF. Indeed, studies employing speckle-tracking echocardiography have shown that in patients with LFLGAS and normal LVEF, LV systolic longitudinal dysfunction manifests as a result of the increased afterload ${ }^{12}$. Additionally, in patients with a low LVEF undergoing coronary artery bypass grafting (CABG) concomitantly to AVR, long-term survival appears to be enhanced. CABG makes the myocardium in certain areas viable, increasing LV function, and exerting a protective effect ${ }^{35,42}$ leading to an improvement in LVEF that was reduced consequently to CAD.

Being the majority of the patients in our meta-analysis operated on AVR+CABG, we believe that the simultaneous CABG procedure might have been beneficial for patients with low LVEF ${ }^{2}$.

Furthermore, we found that LVEF does not impact survival in the noAVR group. We believe that these results are attributable to the fact that conservative management has palliative purposes, thus not improving cardiac function but only dealing with symptoms ${ }^{31}$. This is because both classical and paradoxical LFLGAS can induce heart failure via different mechanisms. Patients with classical LFLGAS have low survival rates as the cardiac function is severely compromised by the small LV cavity size due to LV hypertrophy, severe myocardial fibrosis, and the restrictive pattern of LV filling ${ }^{2}$. On the other hand, some studies suggest that conservative management is not particularly useful in increasing survival in the case of paradoxical LFLGAS as a result of the advanced stage of myocardial fibrosis, the systolic and diastolic dysfunction and the reduced stroke volume index ${ }^{2}$. Moreover, patients with paradoxical aortic stenosis mostly have diffused atherosclerosis and increased stiffness of arterial walls, which decreases arterial compliance ${ }^{2}$. In this situation, medical management is only useful in treating resulting hypertension rather than affecting the aortic valve ${ }^{3}$.

\section{Limitation}

This meta-analysis has some limitations that need to be addressed. First, the number of patients is not high enough to draw definite conclusions. Second, the majority of papers were retrospective studies, so this might have led to inherent selection bias. Third, one included review was an abstract so that we could retrieve limited data from it. Fourth, the papers about reduced LVEF and preserved LVEF were not evenly distributed.

\section{Conclusion}

Patients with LFLGAS have a better survival rate following AVR rather than noAVR. Besides, patients with reduced LVEF seemed to have better survival than patients with preserved LVEF in the AVR group. No difference between low and protected LVEF was found in the noAVR group.

Acknowledgments: We thank Dr Judith Wilson for the English revision of the paper.

Funding: None

Conflict of Interest: None to be disclosed

\section{References}

1. Vogelgesang A, Hasenfuss G, Jacobshagen C. Low-flow/low-gradient aortic stenosis - Still a diagnostic and therapeutic challenge. Clinical cardiology. 2017;40(9):654-659.

2. Pibarot P, Dumesnil JG. Low-Flow, Low-Gradient Aortic Stenosis With Normal and Depressed Left Ventricular Ejection Fraction. Journal of the American College of Cardiology. 2012;60(19):1845-1853. 
3. Clavel M-A, Magne J, Pibarot P. Low-gradient aortic stenosis.European Heart Journal. 2016;37(34):26452657.

4. Clavel MA, Cote N, Pibarot P. Dilemma in the therapeutic management of low-gradient aortic stenosis. Curr Opin Cardiol.2017;32(2):147-151.

5. Tribouilloy C, Levy F, Rusinaru D, et al. Outcome after aortic valve replacement for low-flow/lowgradient aortic stenosis without contractile reserve on dobutamine stress echocardiography. $J$ Am Coll Cardiol. 2009;53(20):1865-1873.

6. Clavel MA. Therapeutic Management of Low-Gradient Aortic Stenosis: First Assess the State of the Schrodinger Cat Before Making a Decision. Circ Cardiovasc Interv. 2017;10(5).

7. Levy F, Laurent M, Monin JL, et al. Aortic valve replacement for low-flow/low-gradient aortic stenosis operative risk stratification and long-term outcome: a European multicenter study. J Am Coll Cardiol. 2008;51(15):1466-1472.

8. Grupper A, Beigel R, Maor E, et al. Survival after intervention in patients with low gradient severe aortic stenosis and preserved left ventricular function. J Thorac Cardiovasc Surg.2014;148(6):2823-2827.

9. Liberati A, Altman DG, Tetzlaff J, et al. The PRISMA statement for reporting systematic reviews and meta-analyses of studies that evaluate health care interventions: explanation and elaboration. PLoS Med.2009;6(7):e1000100.

10. Downs SH, Black N. The feasibility of creating a checklist for the assessment of the methodological quality both of randomised and non-randomised studies of health care interventions. J Epidemiol Community Health. 1998;52(6):377-384.

11. McHugh ML. Interrater reliability: the kappa statistic.Biochem Med (Zagreb). 2012;22(3):276-282.

12. Adda J, Mielot C, Giorgi R, et al. Low-flow, low-gradient severe aortic stenosis despite normal ejection fraction is associated with severe left ventricular dysfunction as assessed by speckle-tracking echocardiography: a multicenter study. Circulation: Cardiovascular Imaging. 2012;5(1):27-35.

13. Bagos PG, Nikolopoulos GK. A method for meta-analysis of case-control genetic association studies using logistic regression.Stat Appl Genet Mol Biol. 2007;6:Article17.

14. Clavel MA, Fuchs C, Burwash IG, et al. Predictors of outcomes in low-flow, low-gradient aortic stenosis: results of the multicenter TOPAS Study. Circulation. 2008;118(14 Suppl):S234-242.

15. Tarantini G, Covolo E, Razzolini R, et al. Valve replacement for severe aortic stenosis with low transvalvular gradient and left ventricular ejection fraction exceeding 0.50. Ann Thorac Surg.2011;91(6):1808-1815.

16. Clavel MA, Dumesnil JG, Capoulade R, Mathieu P, Senechal M, Pibarot P. Outcome of patients with aortic stenosis, small valve area, and low-flow, low-gradient despite preserved left ventricular ejection fraction. J Am Coll Cardiol. 2012;60(14):1259-1267.

17. Mohty D, Magne J, Deltreuil M, et al. Outcome and impact of surgery in paradoxical low-flow, lowgradient severe aortic stenosis and preserved left ventricular ejection fraction: a cardiac catheterization study. Circulation. 2013;128(11 Suppl 1):S235-242.

18. Melis G, Frontera G, Caldentey G, et al. Systolic volume index by Doppler echocardiography is an useful marker for stratification and prognostic evaluation in patients with severe aortic stenosis and preserved ejection fraction. Rev Esp Cardiol (Engl Ed).2013;66(4):261-268.

19. Hermann HC, Pibarot P, Hueter I, et al. Predictors of mortality and outcomes of therapy in low-flow severe aortic stenosis: a Placement of Aortic Transcatheter Valves (PARTNER) trial analysis.Circulation. $2013 ; 127(23): 2316-2326$. 
20. Eleid MF, Sorajja P, Michelena HI, Malouf JF, Scott CG, Pellikka PA. Flow-gradient patterns in severe aortic stenosis with preserved ejection fraction: clinical characteristics and predictors of survival.Circulation. 2013;128(16):1781-1789.

21. Tribouilloy C, Rusinaru D, Marechaux S, et al. Low-gradient, low-flow severe aortic stenosis with preserved left ventricular ejection fraction: characteristics, outcome, and implications for surgery. $J$ Am Coll Cardiol. 2015;65(1):55-66.

22. Annabi M, Dahou A, Burwash I, et al. Aortic Valve Replacement is Superior to Conservative Management in Low-Flow, Low-Gradient Aortic Stenosis independently of the presence of true severe stenosis.Archives of Cardiovascular Diseases Supplements.2019;11(2):246-247.

23. Hachicha Z, Dumesnil JG, Bogaty P, Pibarot P. Paradoxical Low Flow, Low Gradient Severe Aortic Stenosis Despite Preserved Ejection Fraction Reflects More Severe Disease and Poorer Prognosis: Implications for Diagnosis and Treatment. In: Am Heart Assoc; 2006.

24. Ozkan A, Hachamovitch R, Kapadia SR, Tuzcu EM, Marwick TH. Impact of aortic valve replacement on outcome of symptomatic patients with severe aortic stenosis with low gradient and preserved left ventricular ejection fraction. Circulation. 2013;128(6):622-631.

25. Pai RG, Varadarajan P, Razzouk A. Survival benefit of aortic valve replacement in patients with severe aortic stenosis with low ejection fraction and low gradient with normal ejection fraction. The Annals of thoracic surgery. 2008;86(6):1781-1789.

26. Sato K, Sankaramangalam K, Kandregula K, et al. Contemporary outcomes in low-gradient aortic stenosis patients who underwent dobutamine stress echocardiography. Journal of the American Heart Association. 2019;8(6):e011168.

27. Taniguchi T, Morimoto T, Shiomi H, et al. High-versus low-gradient severe aortic stenosis: demographics, clinical outcomes, and effects of the initial aortic valve replacement strategy on long-term prognosis.Circulation: Cardiovascular Interventions. 2017;10(5):e004796.

28. Dayan V, Vignolo G, Magne J, Clavel MA, Mohty D, Pibarot P. Outcome and Impact of Aortic Valve Replacement in Patients With Preserved LVEF and Low-Gradient Aortic Stenosis. J Am Coll Cardiol.2015;66(23):2594-2603.

29. Connolly HM, Oh JK, Schaff HV, et al. Severe aortic stenosis with low transvalvular gradient and severe left ventricular dysfunction:result of aortic valve replacement in 52 patients. Circulation. 2000;101(16):19401946.

30. Awtry E, Davidoff R. Low-Flow/Low-Gradient Aortic Stenosis.Circulation. 2011;124(23):e739-e741.

31. Clavel M-A, Côté N, Pibarot P. Dilemma in the therapeutic management of low-gradient aortic stenosis. Current opinion in cardiology.2017;32(2):147-151.

32. Iung B, Baron G, Butchart EG, et al. A prospective survey of patients with valvular heart disease in Europe: The Euro Heart Survey on Valvular Heart Disease. European heart journal.2003;24(13):1231-1243.

33. Nishimura RA, Holmes DR, Jr., Reeder GS. Percutaneous balloon valvuloplasty. Mayo Clin Proc. 1990;65(2):198-220.

34. Percutaneous balloon aortic valvuloplasty. Acute and 30-day follow-up results in 674 patients from the NHLBI Balloon Valvuloplasty Registry. Circulation. 1991;84(6):2383-2397.

35. Litvack F, Jakubowski AT, Buchbinder NA, Eigler N. Lack of sustained clinical improvement in an elderly population after percutaneous aortic valvuloplasty. Am J Cardiol. 1988;62(4):270-275.

36. Pereira JJ, Lauer MS, Bashir M, et al. Survival after aortic valve replacement for severe aortic stenosis 
with low transvalvular gradients and severe left ventricular dysfunction. J Am Coll Cardiol.2002;39(8):13561363.

37. Cribier A, Eltchaninoff H, Tron C, et al. Treatment of calcific aortic stenosis with the percutaneous heart valve: mid-term follow-up from the initial feasibility studies: the French experience. J Am Coll Cardiol. 2006;47(6):1214-1223.

38. Letac B, Cribier A, Eltchaninoff H, Koning R, Derumeaux G. Evaluation of restenosis after balloon dilatation in adult aortic stenosis by repeat catheterization. American heart journal.1991;122(1):55-60.

39. Lieberman EB, Bashore TM, Hermiller JB, et al. Balloon aortic valvuloplasty in adults: failure of procedure to improve long-term survival. J Am Coll Cardiol. 1995;26(6):1522-1528.

40. Ben-Dor I, Maluenda G, Iyasu GD, et al. Comparison of outcome of higher versus lower transvalvular gradients in patients with severe aortic stenosis and low $(<40 \%)$ left ventricular ejection fraction. The American journal of cardiology.2012;109(7):1031-1037.

41. Clavel M-A, Webb JG, Rodés-Cabau J, et al. Comparison between transcatheter and surgical prosthetic valve implantation in patients with severe aortic stenosis and reduced left ventricular ejection fraction. Circulation. 2010;122(19):1928-1936.

42. Sathyamurthy I, Jayanthi K. Low flow low gradient aortic stenosis: clinical pathways. Indian Heart J. 2014;66(6):672-677.

Table 1 . Patients' characteristics

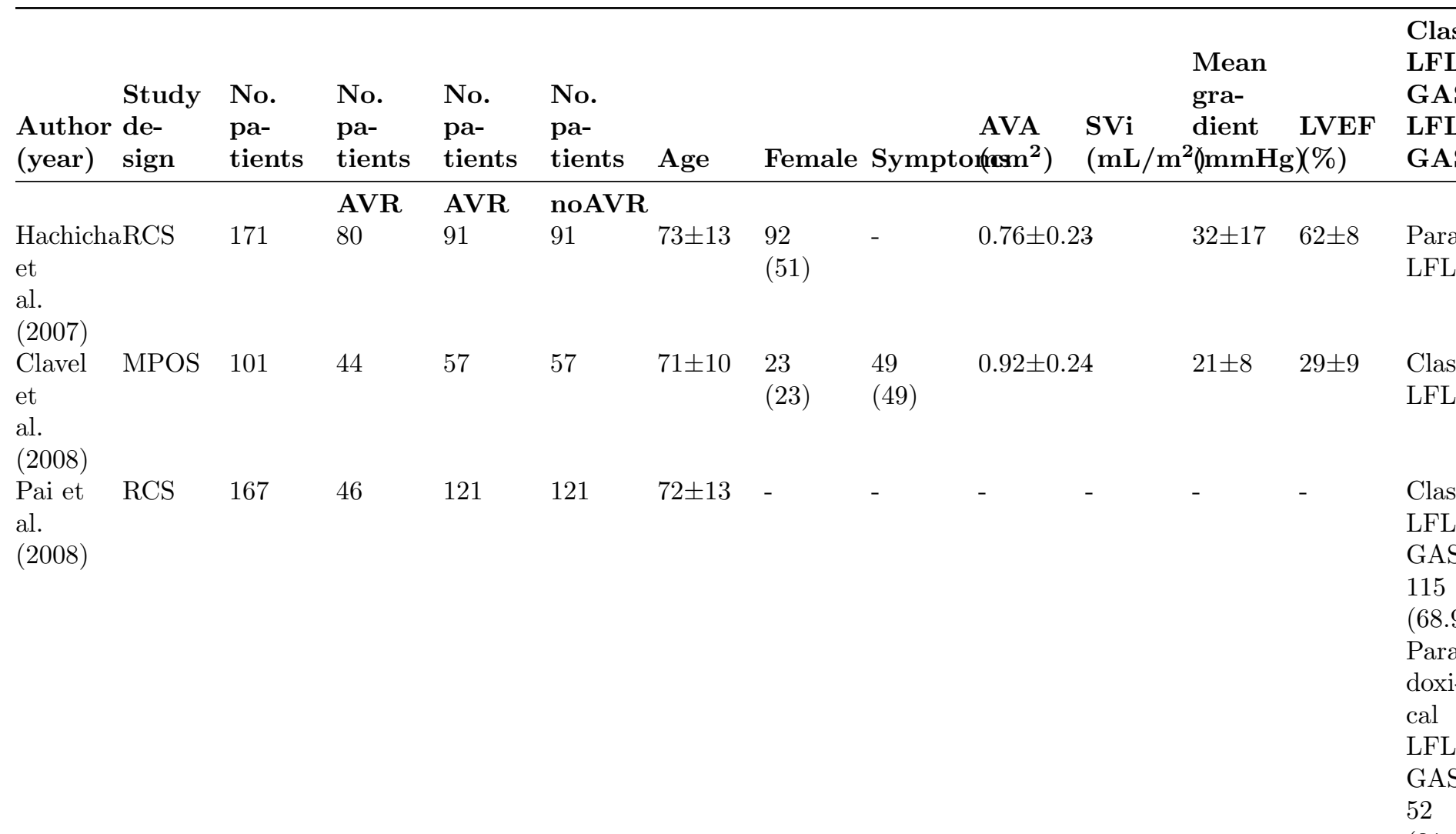

(31. 


\begin{tabular}{|c|c|c|c|c|c|c|c|c|c|c|c|c|}
\hline $\begin{array}{l}\text { Author } \\
\text { (year) }\end{array}$ & $\begin{array}{l}\text { Study } \\
\text { de- } \\
\text { sign }\end{array}$ & $\begin{array}{l}\text { No. } \\
\text { pa- } \\
\text { tients }\end{array}$ & $\begin{array}{l}\text { No. } \\
\text { pa- } \\
\text { tients }\end{array}$ & $\begin{array}{l}\text { No. } \\
\text { pa- } \\
\text { tients }\end{array}$ & $\begin{array}{l}\text { No. } \\
\text { pa- } \\
\text { tients }\end{array}$ & Age & Female & Sympto & $\begin{array}{l}\text { AVA } \\
\left(r^{2} \mathbf{s m}^{2}\right)\end{array}$ & $\begin{array}{l}\mathrm{SVi} \\
\left(\mathrm{mL} / \mathrm{m}^{2}\right.\end{array}$ & $\begin{array}{l}\text { Mean } \\
\text { gra- } \\
\text { dient } \\
{ }^{2} \mathrm{mmHg}^{\mathrm{mmH}}\end{array}$ & $\begin{array}{l}\text { LVEF } \\
)(\%)\end{array}$ \\
\hline $\begin{array}{l}\text { Tarantini } \\
\text { et } \\
\text { al. } \\
(2011)\end{array}$ & iRCS & 101 & 72 & 29 & 29 & $\begin{array}{l}78 \\
{[72-} \\
81]\end{array}$ & $\begin{array}{l}59 \\
(58)\end{array}$ & $\begin{array}{l}90 \\
(88)\end{array}$ & $\begin{array}{l}0.80 \\
{[0.70-} \\
0.89]\end{array}$ & $\begin{array}{l}46 \\
\pm 13\end{array}$ & $\begin{array}{l}33 \\
{[27-} \\
38]\end{array}$ & $\begin{array}{l}0.69 \\
{[0.61-} \\
0.74]\end{array}$ \\
\hline $\begin{array}{l}\text { Clavel } \\
\text { et al. } \\
(2012)\end{array}$ & RCS & 187 & 83 & 104 & 104 & $\begin{array}{l}74 \\
\pm 12\end{array}$ & $\begin{array}{l}96 \\
(51)\end{array}$ & $\begin{array}{l}44 \\
(22)+ \\
104 \\
(56)++\end{array}$ & $\begin{array}{l}0.82 \\
\pm \\
0.16\end{array}$ & $\begin{array}{l}30 \pm \\
4\end{array}$ & $22 \pm 8$ & $62 \pm 8$ \\
\hline $\begin{array}{l}\text { Mohty } \\
\text { et } \\
\text { al. } \\
(2013)\end{array}$ & RCS & 99 & 83 & 16 & 16 & $77 \pm 6$ & $\begin{array}{l}50 \\
(51)\end{array}$ & $\begin{array}{l}88 \\
(89)\end{array}$ & $0.72 \pm 0.1$ & $29 \pm 5$ & $30 \pm 7$ & $70 \pm 11$ \\
\hline $\begin{array}{l}\text { Melis } \\
\text { et } \\
\text { al. } \\
(2013)\end{array}$ & RCS & 40 & 18 & 22 & 22 & $\begin{array}{l}78 \\
{[73.0-} \\
83.0]\end{array}$ & $\begin{array}{l}25 \\
(59.5)\end{array}$ & - & $\begin{array}{l}0.77 \\
{[0.73-} \\
0.81]\end{array}$ & $\begin{array}{l}31 \\
{[30-} \\
32]\end{array}$ & $\begin{array}{l}26 \\
{[24-} \\
29]\end{array}$ & $\begin{array}{l}64 \\
{[62-} \\
67]\end{array}$ \\
\hline $\begin{array}{l}\text { Herrman } \\
\text { et } \\
\text { al. } \\
(2013)\end{array}$ & RCS & 130 & 105 & 25 & 25 & - & - & - & - & - & - & - \\
\hline $\begin{array}{l}\text { Eleid } \\
\text { et } \\
\text { al. } \\
(2013)\end{array}$ & RCS & 53 & 27 & 26 & 26 & $77 \pm 12$ & $\begin{array}{l}18 \\
(34)\end{array}$ & $\begin{array}{l}41 \\
(77)\end{array}$ & $0.87 \pm 0.1$ & $B 1 \pm 3$ & $30 \pm 6$ & $60 \pm 7$ \\
\hline $\begin{array}{l}\text { Ozkan } \\
\text { et } \\
\text { al. } \\
(2013)\end{array}$ & PCS & 135 & 54 & 81 & 81 & - & - & - & - & - & - & - \\
\hline $\begin{array}{l}\text { Tribouill } \\
\text { et } \\
\text { al. } \\
(2015)\end{array}$ & dyCS & 114 & 57 & 57 & 57 & $\begin{array}{l}78.5 \\
{\left[73.5^{-}\right.} \\
86.3]\end{array}$ & $\begin{array}{l}33 \\
(57.9)\end{array}$ & $\begin{array}{l}9 \\
(15.8)\end{array}$ & $\begin{array}{l}0.8 \\
{[0.7-} \\
0.9]\end{array}$ & $\begin{array}{l}30.1 \\
{[27.2-} \\
32.2]\end{array}$ & $\begin{array}{l}30 \\
{[20.5-} \\
34.5]\end{array}$ & $\begin{array}{l}60 \\
{\left[55_{-}^{-}\right.} \\
67]\end{array}$ \\
\hline $\begin{array}{l}\text { Annabi } \\
\text { et al. } \\
(2019)\end{array}$ & PCS & 480 & 269 & 211 & 211 & $\begin{array}{l}75 \pm \\
10\end{array}$ & $\begin{array}{l}136 \\
(28.3)\end{array}$ & & $0.79 \pm 0.1$ & & $26 \pm 7$ & - \\
\hline
\end{tabular}




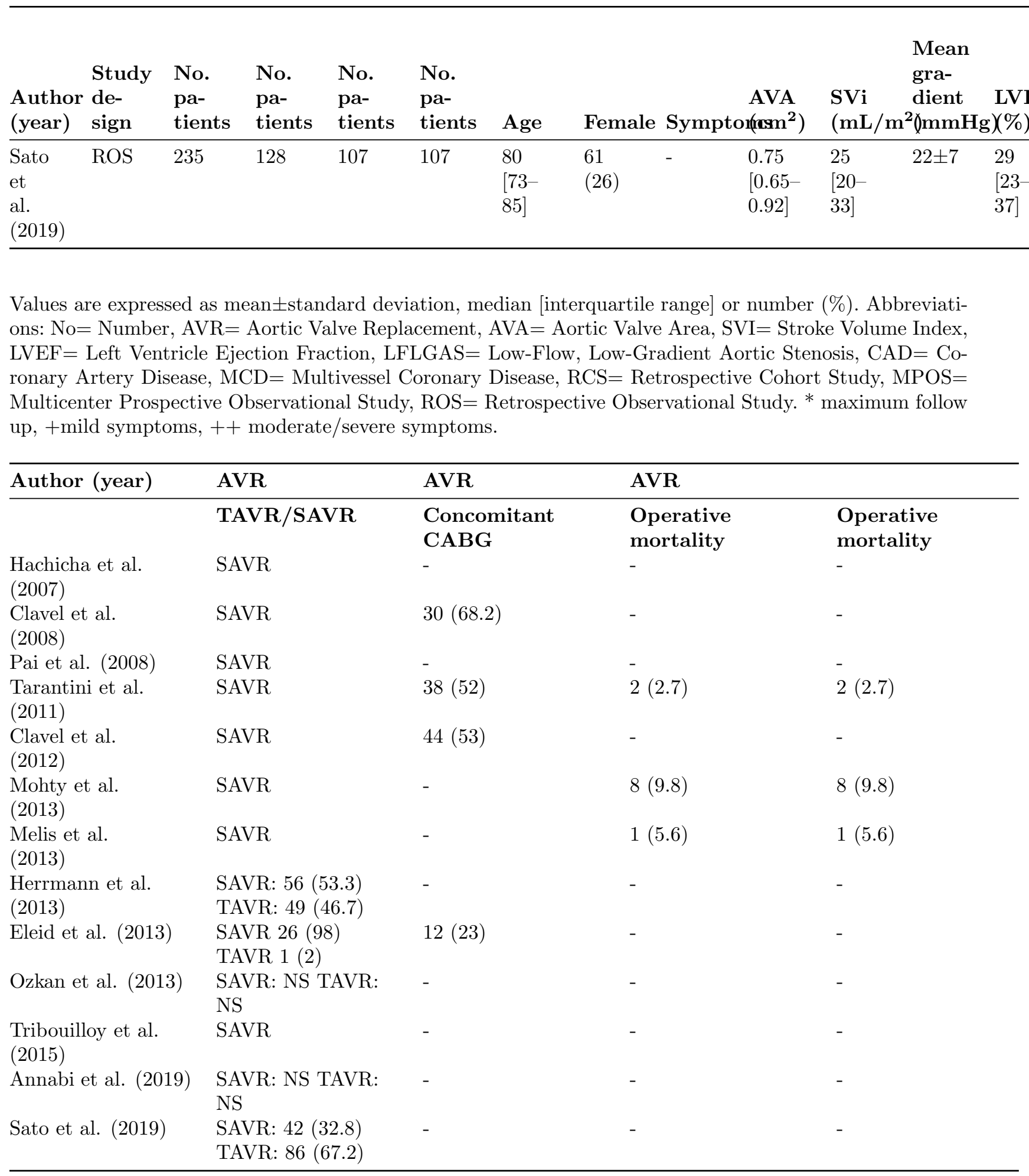

Table 2. Surgical data of AVR

Values are expressed as number (\%). Abbreviations: AVR= Aortic Valve Replacement, SAVR $=$ Surgical 
Aortic Valve Replacement, TAVR $=$ Transcatheter Aortic Valve Replacement, $\mathrm{CABG}=$ Coronary Artery Bypass Grafting.

\section{Figures Legend}

Figure 1. PRISMA flowchart of the selection process

Figure 2. Survival AVR vs noAVR. A. Forest plot.B. Funnel plot. ${ }^{*}$ LVEF $<35 \%$; ${ }^{*}$ LVEF between $35 \%$ and $54 \% ; * * *$ LVEF $>55 \%$.

Figure 3 . Meta regression on the impact of LVEF on survival in A . AVR and B. noAVR

\section{Appendix A. Quality assessment}

\begin{tabular}{|c|c|c|c|}
\hline Item & & Mean & SD \\
\hline 1 & $\begin{array}{l}\text { Study hypothe- } \\
\text { sis/aim/objective } \\
\text { described? }\end{array}$ & 0.92 & 0.27 \\
\hline 2 & $\begin{array}{l}\text { Main outcomes described } \\
\text { in the introduction or } \\
\text { methods? }\end{array}$ & 1.00 & 0.00 \\
\hline 3 & $\begin{array}{l}\text { Participant } \\
\text { characteristics } \\
\text { described? }\end{array}$ & 1.00 & 0.00 \\
\hline 4 & $\begin{array}{l}\text { Contacted participants } \\
\text { representative? }\end{array}$ & 0.04 & 0.20 \\
\hline 5 & $\begin{array}{l}\text { Prepared participants } \\
\text { representative? }\end{array}$ & 0.08 & 0.27 \\
\hline 6 & $\begin{array}{l}\text { Participants recruited } \\
\text { from the same } \\
\text { population? }\end{array}$ & 0.50 & 0.51 \\
\hline 7 & $\begin{array}{l}\text { Participants recruited } \\
\text { over the same time? }\end{array}$ & 0.71 & 0.46 \\
\hline 8 & $\begin{array}{l}\text { Measures and } \\
\text { experimental tasks } \\
\text { described? }\end{array}$ & 0.83 & 0.38 \\
\hline 9 & $\begin{array}{l}\text { Main outcome } \\
\text { measures valid and } \\
\text { reliable? }\end{array}$ & 1.00 & 0.00 \\
\hline 10 & $\begin{array}{l}\text { Task engagement } \\
\text { assessed? }\end{array}$ & 0.33 & 0.48 \\
\hline 11 & $\begin{array}{l}\text { Confounders described } \\
\text { and controlled for? }\end{array}$ & 1.81 & 0.57 \\
\hline 12 & $\begin{array}{l}\text { Statistical tests } \\
\text { appropriate? }\end{array}$ & 1.00 & 0.00 \\
\hline 13 & $\begin{array}{l}\text { Main findings } \\
\text { described? }\end{array}$ & 1.00 & 0.00 \\
\hline
\end{tabular}




\begin{tabular}{llll}
\hline Item & Mean & SD \\
\hline 14 & $\begin{array}{l}\text { Estimates of the random } \\
\text { variability in data main } \\
\text { outcomes? }\end{array}$ & 1.00 & 0.00 \\
15 & $\begin{array}{l}\text { Probability values } \\
\text { reported? }\end{array}$ & 0.96 & 0.20 \\
16 & $\begin{array}{l}\text { Withdrawals and } \\
\text { drop-outs reported? } \\
\text { Data dredging made } \\
\text { clear? }\end{array}$ & 0.27 & 0.45 \\
17 & $\begin{array}{l}\text { Sufficient power } \\
\text { analysis provided? }\end{array}$ & 0.00 & 0.35 \\
\hline
\end{tabular}




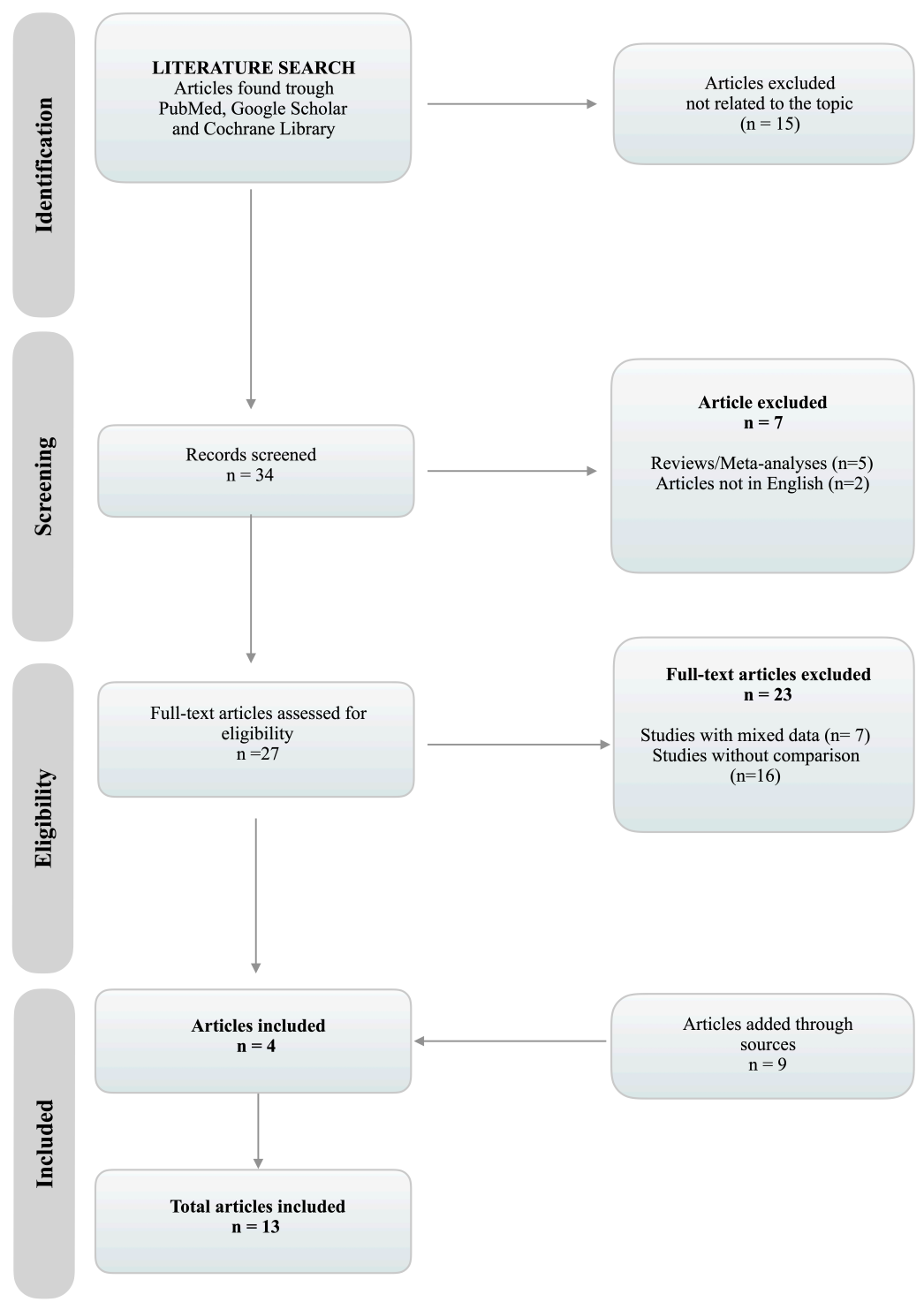



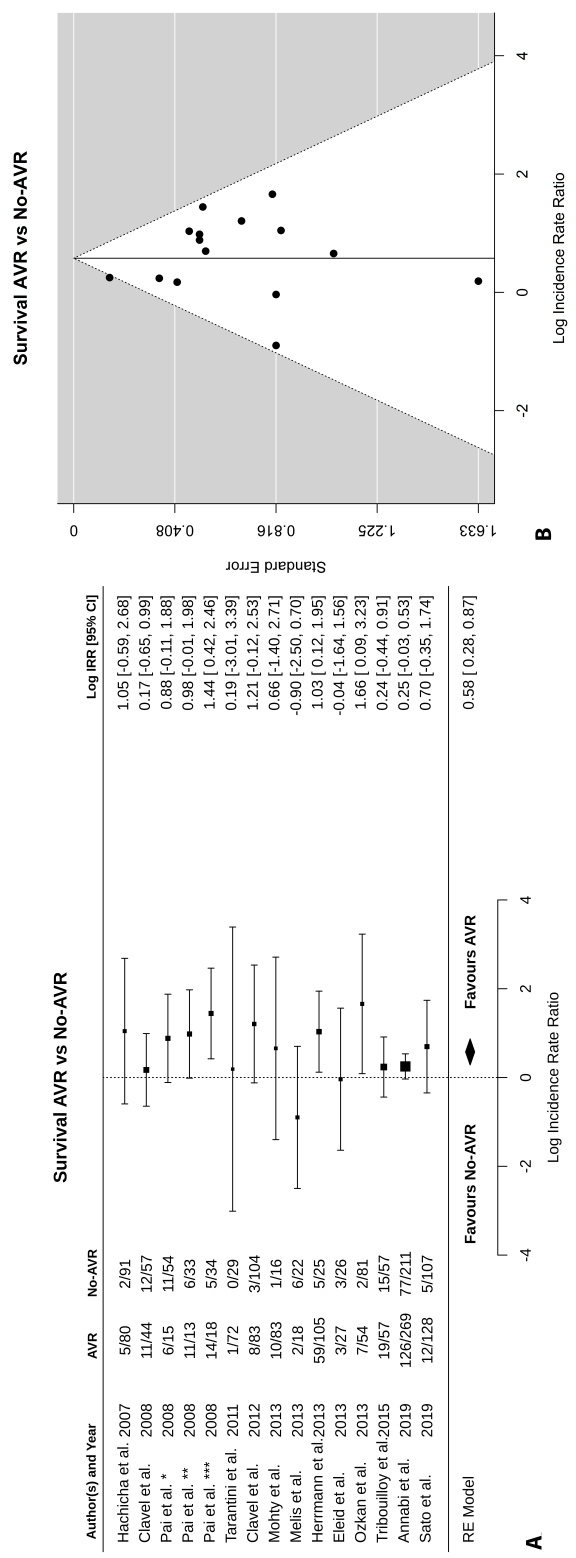
LVEF in AVR

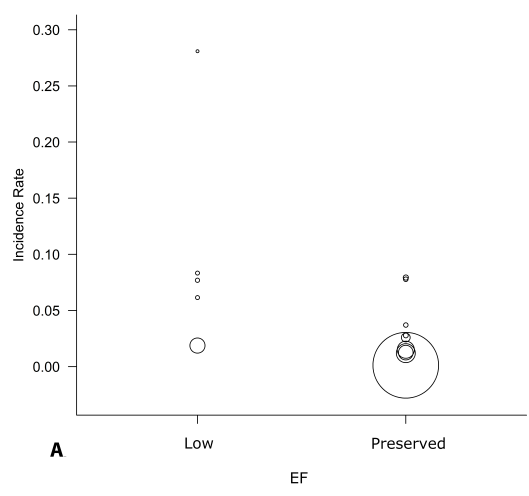

LVEF in No-AVR

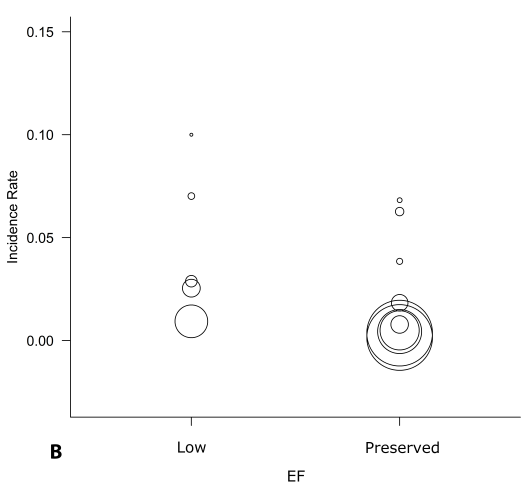

